(1) Aplasia following irradiation accidents where any single dose received was above $400 \mathrm{r}$, since the risk of death is greater than $50 \%$ above this level. ${ }^{1}$

(2) Post-hepatitis aplasia. The mortality of this severe marrow depression is in the region of $10 \%,{ }^{2}$ and marrow transplantation has been successful in two recently reported cases. $^{2} 3$

(3) In severe aplasia when an identical twin donor is available, since marrow can be transfused without pre-graft immunosuppression and graft-versus-host disease does not oocur.

(4) Children with aplasia seem to have a much better chance of a successful graft than do adults. In Stonb's series of 24 patients ${ }^{4}$ a successful graft was obtained in seven of nine patients under 16 years of age compared with four of 13 aged 17 years and older. Furthermore, the encouraging figures that Storb presents represent results of transplantation in patients who had not been supported by full conventional treatmenthalf the patients had bacterial infections at che time of admission and most had received frequent transfusion therapy, both these features prejudicing the successful outcome. As Storb points out, early transplantation before major infection and refractoriness to platelet transfusions occur would offer much better results.

Now that more is known about the problems of graft rejection and graft-versus-host disease in man it seems right to be optimistic about the future of bone marrow transplantation in aplastic anaemia, and it is to be hoped that this procedure will be applied more often in appropriate cases. - I am, etc.

Department of Haematology,

A. J. BARRETT Westminster Hospital.

1 Mathé, G., Amiel. J. L., and Schwarzenberg, I. in Bone Marrow Transplantation and Leucocyt Transfusions, p. 133. S ringfield, Thomas, 197. 2 Camitta, B. M., et al., Blood, 1974, 43, 473.

Royal Marsden Hospital Bone Marrow Transplan

Team, British Medical Fournal, 1974,
4 Storb, R., et al., Blood, 1974, 43, 157.

\section{Idoxuridine in Herpes Zoster}

SIR,-Dr. R. Dawber's paper (8 June, p. $526)$ in which he describes a double-blind trial of $5 \%$ idoxuridine dissolved in dimethyl sulphoxide (DMSO) topically applied at intervals to the visible lesions in zoster is in teresting. However, statements are made in the paper which are inaccurate and must be challenged.

There is little basis for the postulate that "these results broadly agree with those of others." After we first showed that the rela tively insoluble idoxuridine could be dissolved in DMSO and that the solution penetrated the skin and was aotive against herpes simplex virus, ${ }^{1}$ we used intermittent topical application of a $5 \%$ solution to zoster. We applied it to the whole of the affected dermatone, not just to the visible lesions. Zoster, after all, is an affliction of the whole nerve not just the skin. ${ }^{2}$ We hoped that not only the visible skin lesions but most of the affected nerve would be reached. While most patients benefited, some did not, though our results were better than Dr. Dawber's. The reasons for proceeding to trial of a higher concentration of idoxuridine $(40 \%$ in DMSO continuously applied) are given in the paper Dr. Dawber cites. ${ }^{3}$ The nesults were much better; the pain lasted for a much shonter time (median 2.5 days) and, what is mone important, this treatment was sucoessful in nearly all cases. We did not "suggest" that $40 \%$ idoxuridine in DMSO continuously applied for four days was superior to $5 \%$ intermittently applied; we showed that this was so $(\mathrm{P}<0.00001)$.

We have since carried out double-blind trials of $40 \%, 20 \%$, and $5 \%$ idioxuridine in DMSO contimuously applied, and found that $20 \%$ and $5 \%$ were significantly inferior to $40 \%$. Thene was, however, no significant difference between $40 \%$ and $35 \%$ solutions. We have treated over 1,000 patients with $40 \%$ and lately $35 \%$ idloxuridine in DMSO continuously applied. Analysis of the results in 300 cases confirms the predictions of the trials. The median duration of pain was three days; $95.9 \%$ had pain for seven days or less, $79.6 \%$ for four days or lese, and $45.0 \%$ for two days or less. Of the $4.1 \%$ who had pain for more than seven days, only one had pain lasting for as long as 30 days. Of the 300 31 got manked erythema and twa weals fnom the DMSO. Thene was no "maceration" of the skin which we are falsely credited with having described in the tureatment of zoster.

We have momitored our patients carefully for evidience of side effects on hepatic, nenal, and bone-marnow function and on the eyes and found none. The statement that idoxuridine in high concentrations should "be reserved for life-threatening conditions such as herpes simplex encephalitis" is misleading for there is no sound evidence that intravenous idoxunidine has any consistent effect on herpes simplex virus encephalitis. In view of the variety of toxic effects and the relative difficulties of pneparation of intravenous solutions of idoxuridine we and others now use cytosine arabinoside for this purpose.-We are, etc.,

F. O. MaOCALLUM

Department of the Regius Professor of Medicine Radcliffe Infirmary,

1 MacCallum, F. O., and Juel-Jensen, B. E., British Madical fournal, 1966, 2, 805. 2 Esri, M., and Tomlinson, A. M. Fournal of the Juel-Jensen, B. E., et al, British Medical fournal, 1970, 4, 776 .

SIR,-Dr. R. Dawber's trial (8 Jume, p. 526) included pativents from the age of 12 years upwands. Since herpes zoster in young people is a very mild illness with practically no pain and never followed by post-henpetic neuralgia, I think it is wasteful to treat such patients with anything mone than the simplest of measunes.

Dr. Dawiber does not seem to have encountened any patients with post-herpetic neuralgia, even in the controls; the longest mean ( \pm S.E.) durration of pain is reconded as $19.5+1.0$ days. Since the report does not reveal the age distribution of the cases we neally do not know how many elderly people (over 60 years) wene included in the triall, and it is in this age group that post-herpetic neuralgia is a common complication.

Finally, it would have been of interest to know the segmental distribution of the lesions and particularly how ophthalmic herpes was treated.-I am, etc.,

\section{Removal of Fish-hooks}

SIR,-The fishing season is now here and with it the inevitable increase in requests for the removal of fish-hooks from various parts of the body. The usual method for removing these hooks in casualty departments is to infiltrate the area with local anaesthetic, push the barb through the skin, cur off the banb, and remove the remainder of the hook. There is, however, a quick and effective method for removing hooks by using a piece of string. I do not think it is well known but as it saves time and trauma and can be done at the water's edge (as I did today) I think it could be more widely used.

The method is illustrated in the figure:

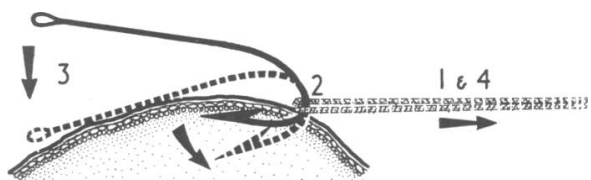

(1) A piece of string about a yard (or a metre) long is tied to form a loop. (2) The loop is passed over the hook and held as close to the skin as possible with the index finger of the left hand. (3) The middle finger and thumb of the same hand depress the eye end of the hook, which disengages the barb and ensunes that during removal the flat outer edge of the hook presses against the skin. (4) The string is taken in the right hand and given a sharp pull with a good follow-through and the hook is removed through its point of entry. Advice to have a tetanus toxoid injection is a sensible precaution. I have used this method many times and large hooks are as easily removed as small ones. Its adoption may help our overworked casualty officers, as any doctor can use this "magic" string whenever a small boy, on the beach or by the river, asks, "Please, sir, can you take hooks out?"-I am, etc.,

Llanelli, Carms

PHILIP A. JONEs

Serum Hepatitis Associated with Repeated Acupunctures

SIR,--The following report of a case of serum hepatitis after acupuncture draws attention to the possibility of this association. I understand that the needles used were sterilized by dipping them in a 1 in 20 solution of tincture of calendula (marigold flowers).

The patient, a woman aged 28, stated that she had had acupunctures every two to three weeks for the past year for the following conditions: periodic bouts of depression, acute bronchitis, acute coryza and sore throat, vaginal thrush, and "strained arms." When she acquired gonorrhoea, however she was treated with penicillin. She also smoked cannabis and occasionally consumed enough aloohol to make herself frankly drunk. Two days after her last acupuncture session she complained of abdominal colic and loss of appetite and noticed that her urine was very dark and her stools pale When admitted to hospital eight days later she was apyrexial, jaundiced, the liver was just palpable, and there were a few fading macular lesions on the forearms. The biochemical findings were those of acute 